\title{
NEWS
}

\section{Climate geoengineering}

\author{
John A. Glaser
}

Published online: 20 March 2010

(c) US Government 2010

A 82 page report Geoengineering the climate released by the Royal Society suggests that proactively engineering certain aspects of the environment may be the only option available to limit global warming in the absence of necessary greenhouse gas (GHG) reductions. The report states that global temperatures are expected to increase by $2^{\circ} \mathrm{C}$ above preindustrial temperatures if GHG emissions are not reduced by $50 \%$ from the 1990 concentrations by 2050 . The Royal Society defines geoengineering as "the deliberate large-scale intervention in the Earth's climate system, in order to moderate global warming." A framework for regulating geoengineering methods is desirable to avoid unintended consequences or irresponsible uses. Two basic classes of geoengineering methods are: carbon dioxide removal (CDR) and solar radiation management (SRM) are advanced as means to ultimately reducing global temperatures. There are major differences in each mode of action, effective timescale, temperature effects, and other consequences. CDR techniques focus on the root cause of climate change by removing GHG from the atmosphere. Direct engineered carbon dioxide capture from the ambient air is identified as the best method to reverse the main cause of climate change. Cost considerations loom prominently for the CDR option. Enhanced weathering or natural removal of $\mathrm{CO}_{2}$ from the atmosphere through reaction with carbonate or silicate rocks could be a longer-termed option. The contribution of this process may be small since it is dominated by exposed surface area effect. Land-use management could provide a significant option to protect and

\section{J. A. Glaser ( $\bowtie)$}

National Risk Management Research Laboratory, US

Environmental Protection Agency, 26 W King Dr, Cincinnati, OH 45268, USA

e-mail: Glaser.John@epa.go enhance terrestrial carbon sinks. SRM techniques attempt to control solar radiation absorption and its effects at the Earth surface to offset effects of increasing GHG concentration in the air. SRM techniques include solar deflectors or shields. Crops with high reflectivity could be useful too.

http://2020science.org/2009/09/01/geoengineering-theclimate-a-clear-perspective-from-the-royal-society/.

\section{Global environmental concerns}

The United Nations Environment Program (UNEP) released its Year Book 2009 which emphasized an elevated sense of global emergency derived from the perception that critical thresholds and tipping points related to global environments could be realized in the short term. The report asserts that climate change is forcing the Earth's systems to critical thresholds or tipping points. The report notes that $60 \%$ of the Earth's assessed ecosystems have been damaged or threatened and significant degradation of $20 \%$ of the globe's terrestrial surface. The report looks to stimulate a "green economy" resulting from the poorly recognized opportunity for governments to establish more environmentally sustainable business practices. Waste is a huge problem as the current annual global output is more than 2 billion metric tons with $1.4 \mathrm{~kg} /$ person per day generated in developing countries. The newest numbers reveal a leveling of waste generation attributable in part to waste minimization and recycling efforts. The report also calls for urgent action in response to GHG emissions by expanding natural carbon storage systems since the existing systems appear to be losing their capacity. There is a genuine fear of a "runaway greenhouse effect" could be encountered if the storage system loss is not replaced. Methane release by permafrost 
thaw is seen as a major contributor to arctic warming and undesirable effects.

http://www.unep.org/geo/yearbook/yb2009.

\section{Metrics for sustainable chemistry}

A concepts paper offers a status report on efforts to identify main features of a chemical reaction useful to the evaluation of undesirable environmental consequences. Sustainability criteria have been used by academic and industry to benchmark innovative technologies. The qualitative relationship between sustainability and chemical processes can be tested through the use of Green Chemistry/Engineering principles. Quantitative evaluation of chemical process sustainability has been organized by mass and energy features that have been introduced to test the environmental impact. Sustainability of chemical reactions must be scrutinized at a level of information beyond the classical metrics of a chemical reaction. The new metrics can be categorized into material efficiency and energy efficiency. Environmental factor, atom economy, carbon efficiency, effective mass yield, environmental quotient, mass intensity, material recovery parameter, reaction mass efficiency, and stoichiometric factor are manifestations of material efficiency metrics. Energy intensity, waste treatment energy, and solvent recovery are similar to those used to measure material efficacy but clearly focus on energy expenditure. Relationship between parameters are considered and graphically depicted on radial pentagons. The authors offer a survey of chemical reactions which evaluates individual chemical reactions for their environmental impact. Catalyzed and non catalyzed reactions, addition reactions, condensation reactions, eliminations, substitutions, metathesis, pericyclic reactions, polymerizations, redox reactions, rearrangements and multicomponent reactions comprise the reaction types considered in this survey. Waste controls, and expert systems have been constructed for general use. The eco-innovation compass is based on a spider heptagon which graphically shows the interrelationship of seven innovative directions. Product-idea tree diagrams are used for their utility to catalyze idea generation and potential outcomes with rules to separate ideas. The use of these techniques can be used to focus attention on the customer's needs and the business values that support environmental values.

ChemSusChem 2009, 2:905-919.

\section{Climate warming effects on plants}

The increasing ambient $\mathrm{CO}_{2}$ concentration in air has been regarded as a potential benefit to plant life. A recent report of the effects of higher $\mathrm{CO}_{2}$ concentrations $(360,510$, $710 \mathrm{ppm}$ ) on a selection of nutritive crops showed significantly reduced development of cassava tubers after 9 months of growth. At the $710 \mathrm{ppm}$ concentration, an $80 \%$ reduction in food yield was observed for the comparison of plants grown under ambient and $710 \mathrm{ppm} \mathrm{CO}_{2}$ concentrations. The plants growing in the higher $\mathrm{CO} 2$ concentrations grew taller, slightly more woody, more stems and smaller leaves. Cassava is an important staple crop as the third largest carbohydrate source in the tropics. The cassava plants were found to be poisonous. The staple crops generally produce cyanogenic glycosides to deter consumption by grazing animals. The cassava plant grown under high $\mathrm{CO}_{2}$ conditions was found to produce three times the cyanide of a plant grown under ambient $\mathrm{CO}_{2}$. In the high- $\mathrm{CO}_{2}$ test plants, the cyanogenic glycoside content in the leaves significantly increased. Since some African human populations consume leaves as a protein supplement, this finding is significant to human health in developing countries. In other studies, $\mathrm{C}_{3}$ plants like rice, wheat, or cassava absorb $\mathrm{CO}_{2}$ to form three carbon molecules when exposed to higher $\mathrm{CO}_{2}$ concentrations, show deficits in calcium, magnesium, phosphorous, and protein by $15 \%$. This study has received some criticism for the experiment design of the reported study. This has prompted the authors to answer the questions by a redesigned study which is expected to reaffirm the reported observations.

Plant Biol 2009, 11(Suppl. 1):76-82; Scientist 2009, 23(10):17-18.

\section{Global photovoltaic production}

The European Commission's Joint Research Center has released the 118 page Photovoltaics Status Report 2009. Solar power generation was greatly assisted by the $80 \%$ increase in production of photovoltaic cells for the 2008 production year. Photovoltaics comprise a solar power technology that generates electricity from the collection of solar radiation and conversion using semiconductor devices or solar cells. Multiples of solar cells can be linked together to form a module or panel. Larger assemblies of modules or panels can be combined to form electricity generating systems, ranging from watts of electricity to multi megawatt output as power stations. Global production of photovoltaics is divided among China (34\%), and EU (26\%) with Japan, Taiwan, and US as minor producers. The global installed capacity is 15 gigawatts with $60 \%$ located in Europe. Spain has increased its capacity by $300 \%$ to 4.8 gigawatts. The report shows photovoltaics as one of the fastest growing renewable technologies.

http://re.jrc.ec.europa.eu/refsys/pdf/PV\%20Report $\% 20$ 2009.pdf. 


\section{Marine litter problems}

In the recent 232 page report Marine Litter: A Global Challenge, the United Nations Environmental Program (UNEP) underscores the need to ban some of the marine debris waste constituents. Plastic components of marine litter include bags, and bottles which account for more than $80 \%$ of the litter collected in a number of the seas around the world. Thin-film, single use plastic bags have been implicated in the choking death of marine life. Tiny pieces of the thin-film plastic arising from the breakdown of marine debris can be consumed by small marine animals forming the food chain base. A survey of North Sea region seabirds showed that $95 \%$ of the sampled population had pieces of plastic in their stomachs. Debris from smoking activities such as cigarette filters, cigar tips, and tobacco packets were found to account for $40 \%$ of marine litter collected in the Mediterranean Sea region. Litter composition changes functionally for each sea region since the activities of each region are different. Surveys of Australian cities show that $80 \%$ of the marine litter can be traced to land-based sources. The ship-breaking yards proximate to the Indian Ocean significantly contributes to the marine debris of that region. There are no systematic estimates of the marine litter found in the 12 participating regions due to differences in methods used to collect and measure the litter. Using production figures to dimension the litter problem, the report estimates that global plastic production at 225 million metric tons each year. Even a small fraction of this quantity could pose a significant threat to marine conservancy objectives. The report calls for focused management of litter within the 12 regions. Harmonization and implementation of environmental policies leading to strategies and measures for litter control could significantly mitigate global marine litter.

www.unep.org/regionalseas/marinelitter/publications/docs/ Marine_Litter_A_Global_Challenge.pdf.

\section{Bioengineered crop limitations}

A controversial 43 page report Failure to Yield: Evaluating the Performance of Genetically Modified Crops released by the Union of Concerned Scientists focusing on the yield performance of genetically engineered corn and soybeans found that the current agricultural biotechnology has not made significant contributions to the intrinsic crop yield. The report further asserts that new technologies under development could be harmful, and calls for research designed to boost production using other technology is warranted. The GM crops have been researched for 20 years and deployed in the field for the last 13 years in the US. Traditional breeding was identified as the major contributor to 20th century crop yield increases. Crops with insect and herbicide-resistant traits show that soybean production has not increased and marginally increased corn yields. The report uses intrinsic or potential yield (highest possible under ideal conditions), and operational yield (actual field conditions) to specify how the new GM varieties have not changed the crop yield structure. Genetic engineering is recognized for the role that it can play to improve operational yield. What is amazing is that the trait changes to GM crop varieties were not claimed to offer enhancement to the intrinsic yield. Furthermore, the changes were specifically targeted to operational yield enhancement. It is true that the benefit of the new pesticidal traits may be obscured when the pest infestation is low. The control of mycotoxins in the food crops attributable to pesticidal trait is not recognized for its value. The issue of intrinsic yield appears to be a bit of a "red herring." There are generally few to no opportunities to compare the yield with a non-GM isoline due to the fact that the seed producers do not keep the same line in production. According to the report, US crop yields have not been significantly affected by the newly installed pesticidal traits. In the case of corn rootworm, yield is one part of the equation but equally important is the ability to harvest the corn. When corn is infested with rootworm, the corn plant structure becomes unstable. Wind or other environmental factors lead to the corn plant dropping to the soil surface from which the plant tries to regain its upright structure. This realignment often leads to cork-screwing of the plant which at harvest becomes a major problem. The general query of the report is to evaluate the GM crops for their ability to address the increasing needs of the world's population for food. The report conclusion advances the idea that it would be possibly more useful to expand the crop development schemes to include overlooked, cheaper or non-popular strategies to enhance food yield from food crops in general. An interesting exchange of opinions concerning this report was published in Nature Biotechnology.

http://www.ucsusa.org/assets/documents/food_and_ agriculture/failure-to-yield.pdf, Nat Biotechnol 2009, 27: 801-803.

\section{Hydrogen storage}

Hydrogen as a fuel and energy source is beginning to be explored for the role it can play to reduce GHG emissions. At first glance, hydrogen as a fuel is a no-brainer. The simple combustion of hydrogen to form water is simple and eminently clean. Superficial inspection of hydrogen generation, handling, and distribution identifies significant obstacles to the apparently simple and clean 
fuel use. Hydrogen exists generally as two physical states of gas and liquid. With a boiling point of $-253^{\circ} \mathrm{C}$ and $2 \mathrm{~g}$ of $\mathrm{H}_{2}$ occupying 22.41 at STP, storage constraints begin to appear. Liquid hydrogen ( $\mathrm{LH})$ is a reasonable way to convey larger quantities of hydrogen but there is a significant cost to liquefaction. The low temperatures of $\mathrm{LH}$ also require special materials of construction for the containers to hold LH. Cryo-adsorption is possible and is the topic of extensive research. Other adsorption approaches, zeolites, carbon materials, metal-organic frameworks, and polymers with intrinsic microporosity are areas of research. Considering the quantity of hydrogen and the time expected for delivery as in the case of autos, some of these options cannot meet the specifications required for operation. Chemical hydrides are another storage option which range from reversible hydride systems to amine-borane adducts and amides/ imides. Liquid hydrogen carriers such as organic liquids comprised of cyclic hydrocarbons that undergo hydrogenation and dehydrogenation with some facility are another option. The source of hydrogen is very important to these directions. Reforming hydrocarbons is the current industrial process which provides hydrogen to ammonia synthesis as well as other uses. The reforming process can be sufficiently miniaturized to consider mating it with a polymer electrolyte membrane (PEM) fuel cell for possible mobile applications. Considering all the options discussed, not one is advanced to a satisfactory level of performance. Heat management is critical to all options. LH is considered the most promising option for large hydrogen volume storage. High-surface-area materials for the adsorptive storage of hydrogen appear to be close to the storage limits derived from physical considerations. It is to be expected that hydrogen will play a role as a fuel but its fit in the range of applications is not discernable presently. It is also important to remember that reforming synthesis of hydrogen has a significant carbon footprint.

Angew Chem Int Ed 2009, 48:6608-6630.

\section{Methanol from carbon dioxide}

The reduction of carbon dioxide as a GHG in ambient air is important to climate change. Options to store the nonpolar $\mathrm{CO}_{2}$ molecule has been found to be quite difficult but progress with high-surface area materials continues to show promise. There is also interest in the transformation to stable molecules that can contribute as useful chemicals as sources of energy and chemical feedstocks. A number of catalytic conversion chemistries are known for the conversion of $\mathrm{CO}_{2}$ to methanol.

$$
\mathrm{CO}_{2} \rightarrow \mathrm{CH}_{3} \mathrm{OH}
$$

This conversion has recently been accomplished with silanes over $\mathrm{N}$-heterocyclic carbine catalysts. The reaction is comprised of 1,3-bis(2,4,6-trimethylphenyl)imidazolium carboxylate (NHC) dissolved in $N, N$-dimethylformamide under a $\mathrm{CO}_{2}$ atmosphere to which diphenylsilane is added at room temperature. At low concentrations, the NHC catalyst was active and the silane was effect at low concentrations. Future research is focused on the replacement of the hydrogen source, silane with alternative hydrogen sources.

A recent report uses a "frustrated Lewis pair" formed from 2,2,6,6-tetramethylpiperdine and perflurotriphenyl borane leading to a quantitative yield of methanol at $100^{\circ} \mathrm{C}$ in toluene. The advantage of this selective chemistry is that it can occur at low pressures (1-2 atm) without the use of any metal mediated procedures. The stability of the chemical system must be evaluated with an eye to determining if the reaction can be made catalytic.

Angew Chem Int Ed 2009, 48:3322-3325; 2009, 48:9839-9843.

\section{Changes in American agriculture to realize biofuel and bioploymer roles}

The 258 page proceedings of the 20th annual conference of the National Agricultural Biotechnology Council (NABC), held in Columbus, Ohio, are available at the NABC site. The NABC 20: Reshaping American Agriculture to Meet its Biofuel and Biopolymer Needs offers a perspective on Biotrends, Food \& Fuel, Research \& Technology, and Energy \& Policy. The proceedings are organized into Overview, Breakout sessions, Plenary sessions, Banquet and Luncheon presentations, and a report from students in attendance. The plenary sessions are further subdivided into three modules: Megatrends Reshaping Agriculture, Optimizing the Value of Co-Products and Byproducts, Policy Issues Impacting Agriculture and Bioenergy in twelve presentations ranging from renewable materials to the scientific challenges underpinning the food-fuel debate. The text of the presentations is well organized and navigation through the proceedings is assisted by a well organized page index. Additional unpublished information is available at the web site.

http://nabc.cals.cornell.edu/.

\section{Virtual journal issues}

The inaugural Virtual Issue of Macromolecules "Click Chemistry in Macromolecular Science", which is an 
assemblage of 27 papers published in Macromolecules in 2008 or 2009 which utilize click chemistry as a tool to solve questions related to materials syntheses. "Click chemistry" denotes a reaction having the following characteristics: quantitative, rapid, no byproducts, no side reactions, functional group tolerant, mild reaction conditions, and broadly applicable. Access to articles in Macromolecules Virtual Issues will remain free to nonsubscribers until the next Macromolecules Virtual Issue has been released. The second virtual issue is organized on the topic of "Polymers from Renewable Resources" and contains 17 papers published in Macromolecules during 2008 and 2009. The focus of the virtual issue is the synthesis of new renewable monomers and catalytic conversion of the new and more established renewable monomers into polymers. These virtual issues may provide highly useful collections of information on subjects important to our research interests. http://pubs.acs.org/page/mamobx/vi/1 or http://pubs.acs. org/page/mamobx/vi/2.

\section{New journals}

The new journal Current Opinion in Environmental Sustainability is an Elsevier journal in the Current Opinion series considering a spectrum of aspects related to environmental sustainability. The journal will be organized into six sections: climate systems, human settlements and habitats, energy systems, terrestrial systems, carbon and nitrogen cycles, and aquatic systems. Each of the sections will be reviewed yearly. Contributions to this journal should be of general interest to the readership of Clean Technologies and Environmental Policy.

Curr Opin Environ Sustain 2009, 1:1-3. 